\title{
Influence of sirolimus-induced TGF- $\beta$ secretion on mouse Treg cell proliferation
}

\author{
J.N. Li ${ }^{1 *}$, J.X. Li ${ }^{1 *}$, H.L. Huang ${ }^{1 *}$, X.L. Zhu', H. Ding ${ }^{1}$, C.F. Huang ${ }^{1}$, J. Lin ${ }^{1}$, \\ J.G. Huang ${ }^{1}$, Z.C. Wu ${ }^{1}$, M. Ashraf ${ }^{2}$, Y.G. Wang ${ }^{3}$, X.K. Li ${ }^{4}$, S.Y. Zheng ${ }^{1}$, \\ J.M. Chen', H.M. Guo ${ }^{1}$, J. Zhuang ${ }^{1}$ and P. Zhu' ${ }^{1}$ \\ 1Department of Cardiovascular Surgery, Guangdong Cardiovascular Institute, \\ Guangdong General Hospital, Guangdong Academy of Medical Sciences, \\ Guangzhou, China \\ ${ }^{2}$ Department of Pharmacology, UIC College of Medicine, Chicago, IL, USA \\ ${ }^{3}$ Department of Pathology \& Lab Medicine, College of Medicine, \\ University of Cincinnati, Cincinnati, OH, USA \\ ${ }^{4}$ Division of Transplantation Immunology, \\ National Research Institute for Child Health and Development, Tokyo, Japan \\ *These authors contributed equally to this study. \\ Corresponding authors: J. Zhuang / P. Zhu \\ E-mail: zhuangjianzggd@aliyun.com / tanganqier@163.com
}

Genet. Mol. Res. 14 (4): 18569-18579 (2015)

Received January 8, 2015

Accepted July 10, 2015

Published December 28, 2015

DOI http://dx.doi.org/10.4238/2015.December.28.4

ABSTRACT. We examined the effects of co-culturing CD4+ CD25+ Treg cells with sirolimus or cyclosporin A on Treg cell proliferation and differentiation and on transforming growth factor- $\beta$ (TGF- $\beta$ ) and Foxp3 expression. CD4+ CD25+ Treg cells were harvested from mononuclear cells of spleens of C57BL/6 mice using immunomagnetic beads and divided into control, sirolimus, and cyclosporine groups. Following a 96-h co-culture, Treg cells were assayed by flow cytometry. FoxP3 and TGF- $\beta$ mRNA levels and secretion were assayed by reverse transcription polymerase chain reaction and enzyme-linked immunosorbent assay. Smad protein of the TGF- $\beta$ signaling pathway was assayed by western blot and its effect on CD4+ CD25+ FoxP3+ Treg cell proliferation was 
determined. Sirolimus-promoted differentiation and proliferation was examined using a TGF- $\beta$ neutralizing antibody. Sirolimus-treated CD4+ T cell TGF- $\beta$ secretion increased $2.5 X$ over control levels $(P<0.01)$, but that of the cyclosporine group decreased marginally $(P>0.05)$. The CD4+ cell proportion decreased significantly $(41.25$ vs $69.22 \%, P<0.01)$ and slightly (65.21 vs 69.22, $\mathrm{P}>0.05)$ in the cyclosporine and sirolimus groups, respectively. T cell Foxp3 mRNA expression was significantly higher in the sirolimus-treated than in the cyclosporine (53.7 vs $40.2 \%, \mathrm{P}<0.05)$ and control groups $(P<0.01)$, but was significantly lower in the cyclosporine group than in controls (23.6 vs $40.2 \%, \mathrm{P}<0.01$ ). Overall, sirolimus promoted CD4+ CD25+ Treg cell proliferation and growth in vitro, whereas cyclosporin A inhibited proliferation. Sirolimus might promote CD4+ CD25+ FoxP3+ regulatory $T$ cell proliferation by inducing TGF- $\beta$ secretion in vivo.

Key words: Sirolimus; Cyclosporin A; Regulatory T cells; Foxp3; Mice; Transforming growth factor- $\beta$

\section{INTRODUCTION}

The degree of allograft rejection or transplantation tolerance depends on the degree of balance between effector and regulatory T cells (Tregs) (Taams et al., 2003; Sakaguchi, 2004; Lan et al., 2005). Recently, the regulation of effector T cells by Tregs has been promoted by using immunosuppressive drugs to effectively prevent rejection; this strategy has become a primary research focus in the field. It has been reported that signaling by transforming growth factor- $\beta$ (TGF- $\beta$ ) was the key to the activation of Tregs (Zheng, 2008). Researchers found that sirolimus could promote the production of TGF- $\beta$, but whether there was a relationship between its effects on Tregs and on TGF- $\beta$ remained unclear (Burchill et al., 2007; Yao et al., 2007; Zeiser et al., 2008). To address this question, we observed the changes in the proportion of Treg cells and the secretion level of TGF- $\beta$ following co-culture with sirolimus, investigated the proliferation of Treg cells and the expression of Foxp3 therefrom, and studied whether sirolimus induced the proliferation of Tregs by promoting the production of TGF- $\beta$. We further examined whether sirolimus played related roles in immune regulation by co-culturing CD4+ cells with either cyclosporin A or sirolimus, and comparing the effects of cyclosporin A and sirolimus to the differentiation of Tregs mediated by TGF- $\beta$ in vitro and in vivo. We suggest that the results of these studies provide an experimental basis for the administration of immunosuppressive agents after cardiac transplantation in the clinic.

\section{MATERIAL AND METHODS}

\section{Experimental animals, materials, and regents}

Male C57BL/6 $(\mathrm{H}-2 \mathrm{~Kb})$ and BALB/C $(\mathrm{H}-2 \mathrm{Kd})$ mice aged 8 to 12 weeks (SPF grade) weighing 20 to $25 \mathrm{~g}$ were provided by the Center of Laboratory Animal Science of ShangHai BiKai. They were housed in cages in a laboratory animal care facility of the Department of Immunology of the Second Military Medical University and fed a standard lab chow diet. Sirolimus (5 mg/5 $\mathrm{mL}$ ) was purchased from Wyeth Pharmaceuticals Inc. (Rouses Point, NY, USA); cyclosporin A (50 $\mathrm{mg} / 5 \mathrm{~mL}$ ) was purchased from Novartis AG (Basel, Switzerland); TRIzol Reagent was purchased 
from Invitrogen (Carlsbad, CA, USA); chloroform was purchased from the China National Pharmaceutical Group Corporation (Beijing, China); and agarose was purchased from SinoAmerican Biotechnology Co., Ltd. (Henan, China). All cells were cultured at $37^{\circ} \mathrm{C}$ in a humidified atmosphere of $5 \% \mathrm{CO}_{2}$. The primers for Foxp3 and TGF- $\beta 1$ were synthesized by Sangon Biotech (Shanghai) Co., Ltd. (Shanghai, China). Primer sequences are as follows: Foxp3: forward primer: 5'-TCC GAT TAC CGG CGC ATC ACG-3', reverse primer: 5'-CTC CAG CAG CTC GAAAAG GCA -3'; TGF- $\beta 1$ : forward primer: 5'-CCT TCG TGC CGT CTAATA-3', reverse primer: 5'-ACC TCT TTA GCA TAG TAG TCC GC-3'.

\section{Instruments}

The instruments and equipment used in this study included a W-CJ-IF super-clean worktable (Suzhou Purification Technology Co., Ltd., Suzhou, China); an HF240 incubator containing $5 \% \mathrm{CO}_{2}$ (Sigma-Aldrich, St. Louis, MO, USA); a low temperature high speed bench centrifuge (B. Braun Biotech International Co., Ltd., Melsungen, Germany); an EPICS X Flow Cytometry instrument (Beckman Coulter Co., Ltd. Brea, CA, USA); an ultraviolet micro spectrophotometer (Amersham Pharmacia Biotech Co., Ltd., Piscataway, NJ, USA); a Perkin Elmer-2231 PCR system (Perkin Elmer, Waltham, MA, USA); a KB2117-II electrophoresis apparatus (Sibas Biotechnology Development Co., Ltd., Shanghai, China); and a 60-2517 image acquisition and analysis system (Media Cybernetics Co., Ltd., Rockville, MD, USA).

\section{Separation of CD4+ T cells}

\section{Preparation of single cell suspensions from spleen}

The C57BL/6 mice were sacrificed by cervical dislocation and spleens were collected under aseptic conditions. Harvested tissue was placed in $20 \mathrm{~mL}$ RPMI 1640 medium containing $2 \%$ fetal bovine serum (FBS) and was ground repeatedly on an aseptic 100-eye grinding steel network, then filtered twice. The suspended cells were collected by centrifugation at $1000 \mathrm{r} / \mathrm{min}$ for $10 \mathrm{~min}$, and then Tris- $\mathrm{NH}_{4} \mathrm{CL}$ buffer was added to the supernatant to disrupt the blood cells. After a 5-min incubation and centrifugation at $1000 \mathrm{r} / \mathrm{min}$ for $5 \mathrm{~min}$, the cells were resuspended with phosphate buffered saline (PBS) and centrifuged again at $1000 \mathrm{r} / \mathrm{min}$ for $5 \mathrm{~min}$. Finally, the supernatants were removed and the cell concentration was adjusted to $10^{7} / \mathrm{mL}$.

\section{Sorting of CD4+ T cells with microbeads}

Prior to sorting, $1 \times 10^{7}$ cells were resuspended with sorting buffer containing $5 \mathrm{~g} / \mathrm{L}$ bovine serum albumin and $2 \mathrm{M}$ EDTA, followed by the addition of a biotin-antibody cocktail (Miltenyi Biotec, $10 \mathrm{ul} / 10^{7}$ cells). The solution was mixed, incubated at $4^{\circ} \mathrm{C}$ for $10 \mathrm{~min}$, then Anti-Biotin MicroBeads were added; the solution was mixed again, incubated at $4^{\circ} \mathrm{C}$ for $15 \mathrm{~min}$, washed with sorting buffer, and centrifuged at $1000 \mathrm{r} / \mathrm{min}$ for $10 \mathrm{~min}$. The suspended cells were resuspended with $500 \mu \mathrm{L}$ sorting buffer. An LD separation column was placed in the Midi MACS cell-sorting instrument and washed twice with $1 \mathrm{~mL}$ sorting buffer, followed by the addition of the cell suspensions into the separation column. CD4+ T cells were collected from the sorting column by negative selection.

\section{Sorting of CD4+ CD25+ T cells with microbeads}


CD4+ T cells were collected as described above. Then, the supernatants were removed after centrifugation at $1000 \mathrm{r} / \mathrm{min}$ for $5 \mathrm{~min}$ and cells were washed once with PBS. To this, 10 $\mu \mathrm{g}$ anti-CD25-PE antibody (Biolegend) was added and the mixture was incubated at $4{ }^{\circ} \mathrm{C}$ for 30 min, and pure CD4+ CD25+ T cells were collected after centrifugation at $300 \mathrm{~g}$ for $10 \mathrm{~min}$ and washed. The purity of the CD4+ CD25+ T cells was determined to be greater than $95 \%$ by flow cytometric confirmation.

\section{CD4+ T cell proliferative assay and sirolimus treatment}

The $\left[{ }^{3} \mathrm{H}\right]-\mathrm{TdR}$ incorporation method was used to detect the proliferation level of CD4+ T cells from the spleen. Pure CD4+ T cells obtained as described above were used as reaction cells and the cell concentration was adjusted to $2 \times 10^{6} / \mathrm{mL}$ with RPMI-1640 culture medium. Then, 100 $\mu \mathrm{L}$ were seeded on 96 -well plates and divided into the following groups: group $\mathrm{A}$ (control group) consisted of pure reaction cells; group B consisted of pure reaction cells + cyclosporine A (10 nM); and group $\mathrm{C}$ was pure reaction cells + sirolimus $(20 \mathrm{ng} / \mathrm{mL})$; three parallel wells were established for each group. Then, $5 \mu \mathrm{g} / \mathrm{mL}$ anti-mouse aCD3 monoclonal antibody (Biolegend) was added to each group and all cells were cultured at $37^{\circ} \mathrm{C}$ in a humidified atmosphere of $5 \% \mathrm{CO}_{2}$ for 3 days. At $16 \mathrm{~h}$ prior to the ending of the incubation period, $1 \mu \mathrm{L} \mathrm{Ci}\left[{ }^{3} \mathrm{H}\right]-\mathrm{TdR}$ was added into each well. The culture was collected by a cell collection instrument and placed on a glass fiber filter, and cells were fixed with $100 \mathrm{~g} / \mathrm{L}$ trichloroacetic acid, washed with $95 \%$ ethanol, and dried at $60^{\circ} \mathrm{C}$ prior to addition into scintillation liquid. A liquid scintillation counter was used to detect the incorporation value of $\left[{ }^{3} \mathrm{H}\right]-\mathrm{TdR}$ into cells. Results are reported as means $\pm \mathrm{SD}$ (pulse number/min).

\section{Detection TGF- $\beta$ expression in CD4+ CD25+ T cells by polymerase chain reaction (PCR)}

RNA was isolated from CD4+ CD25+ T cells by TRIzol (Invitrogen) using standard procedure. The total RNA concentration was determined spectrophotometrically at 260 and 280 $\mathrm{nm}$. Then the RNA was subjected to reverse transcription amplification using the Access RT-PCR System according to the manufacturer protocol. PCR conditions were as follows: initial denaturation at $95^{\circ} \mathrm{C}$ for $4 \mathrm{~min}$, followed by 30 cycles of $95^{\circ} \mathrm{C}$ for $30 \mathrm{~s}, 56^{\circ} \mathrm{C}$ for $30 \mathrm{~s}, 72^{\circ} \mathrm{C}$ for $30 \mathrm{~s}$, then by an 8 -min elongation at $72^{\circ} \mathrm{C}$. PCR products were separated using $1.2 \%$ agarose gel electrophoresis under $80 \mathrm{~V}$ for $1 \mathrm{~h}$, observed under UV light, and analyzed using a Gel-Pro IMAGER 60-2517. The OD value of each band was determined and the comparative values of TGF- $\beta$ and $\beta$-actin: forward primer: 5'-AAC AGT CCG CCT AGA AGC AC-3', reverse primer: 5'-CGT TGA CAT CCG TAA AGA CC-3' were calculated, which represent the relative expression of the target RNA. The calculation formula was as follows: relative amount $=$ OD value of target band / OD value of $\beta$-actin band.

\section{CD4+ CD25+ T cell proliferation, Foxp3 expression, and sirolimus treatment}

The CD4+ CD25+ T cells obtained as described above were diluted to $2 \times 10^{6} / \mathrm{mL}$ with RPMI1640 culture medium, and $100 \mu \mathrm{L}$ cells were seeded on 96-well plates and divided into experimental groups as described for the CD4+ analysis above. IL-2 (100 U/mL) was added to each group along with $5 \mu \mathrm{g} / \mathrm{mL}$ anti-mouse $\alpha \mathrm{CD} 3$ and $2 \mu \mathrm{g} / \mathrm{mL}$ aCD28 (Biolegend) monoclonal antibodies, and all cells were then cultured at $37^{\circ} \mathrm{C}$ in a humidified atmosphere of $5 \% \mathrm{CO}_{2}$ for 7 days. A flow cytometer was used to detect the rate of CD4+ CD25+ T cells and the phenotype change of Foxp3+ expression. 


\section{Cytotoxicity of CD4+ CD25+ T cells}

The CD4+ CD25+ and CD4+ CD25- T cells of C57BL/6 mouse spleens were sorted by microbeads, as described above. The CD4+ CD25- T cells $\left(2 \times 10^{6} / \mathrm{mL}\right)$ of C57BL/6 mice were used as the reactive $T$ cells. The spleen cells of BALB/c mice were pretreated with mitomycin $C$ ( 30 $\mu \mathrm{g} / \mathrm{mL}$ ) for $30 \mathrm{~min}$ and acted as the stimulatory cells. The reactive and stimulant cells were mixed at a ratio of $10: 1$ and added on 96 -well plates with medium containing $10 \%$ FBS. The CD4+ CD25+ T cells and reactive cells were mixed in different ratios $(1: 1,1: 2$, and 1:4) at MLR system separately; the control groups included a reaction group and a CD4+ CD25+ T cell group, and there were three parallel wells for each group. All cells were cultured at $37^{\circ} \mathrm{C}$ in a humidified atmosphere of $5 \% \mathrm{CO}_{2}$ for 3 days. At $16 \mathrm{~h}$ prior to the end of the incubation period, $1 \mu \mathrm{L} \mathrm{Ci}\left[{ }^{3} \mathrm{H}\right]-\mathrm{TdR}$ was added into each well. The culture was collected by a cell collection instrument and placed on a glass fiber filter, and cells were fixed with $100 \mathrm{~g} / \mathrm{L}$ trichloroacetic acid, washed with $95 \%$ ethanol, and dried at $60^{\circ} \mathrm{C}$ prior to addition into scintillation liquid. A liquid scintillation counter was used to detect the incorporation value of $\left[{ }^{3} \mathrm{H}\right]-\mathrm{TdR}$ into cells. Results of the numbers of surviving cells in each group are reported as means \pm SD (pulse number/ min).

\section{Detection of the expression of SMAD2/3 and Foxp3 by western blotting}

The CD4+ CD25+ T cells sorted by microbeads were divided into groups as described previously. IL-2 (100 U/mL) was added to each group along with $5 \mu \mathrm{g} / \mathrm{mL}$ anti-mouse aCD3 and $2 \mu \mathrm{g} / \mathrm{mL}$ aCD28 monoclonal antibodies, and all cells were then cultured at $37^{\circ} \mathrm{C}$ in a humidified atmosphere of $5 \% \mathrm{CO}_{2}$. Cells were collected after 3 days, and $3 \mathrm{~mL} / \mathrm{g}$ RIPA buffer and PMSF were added. Cells were disrupted by repeated aspiration by a pipette and incubated on ice for $30 \mathrm{~min}$. Samples were transferred into new Eppendorf tubes and centrifuged at $12,000 \mathrm{r} / \mathrm{min}$ at $4^{\circ} \mathrm{C}$ for 30 min. The supernatant was carefully transferred into new tubes and preserved at $-20^{\circ} \mathrm{C}$ until further use. The protein quantity was determined using a BCA Protein Assay Kit (Nanjing KeyGen Biotech. Co. Ltd., China), and RIPA buffer was used as the blank control. Each experiment was repeated 4 times. Proteins from CD4+ CD25+ T cells were harvested with RIPA lysis buffer (Nanjing KeyGen Biotech. Co. Ltd., China) containing phosphatase inhibitor cocktail and protease inhibitor cocktail from different groups at indicated time points. Proteins $(60 \mu \mathrm{g})$ were subjected to electrophoresis and transferred onto PVDF membranes (Bio-Rad, Hercules, CA, USA). The membranes were blocked with $3 \%$ skim milk containing $0.1 \%$ sodium azide (Nanjing KeyGen Biotech. Co. Ltd., China) for $1 \mathrm{~h}$ at room temperature and then incubated with primary antibodies overnight at $4^{\circ} \mathrm{C}$. After being washed three times, membranes were probed with horseradish peroxidase-conjugated secondary antibodies for $1 \mathrm{~h}$ at room temperature. GAPDH was used to normalize protein loading. The primary antibodies used are as follows: GAPDH (1:2000; Cell Signaling Technology, Beverly, MA, USA), SMAD2/3 (1:2000; Abcam, Cambridge, MA, USA), Foxp3 (1:2000; Santa Cruz Biotechnology). Blots were developed with an enhanced chemiluminescence system. The results of western blotting were scanned and analyzed by a Gel-Pro Analyzer (Ver 3.0).

\section{Statistical analysis}

Data were analyzed with the SPSS 12.0 software (SPSS, Chicago, IL, USA). Enumeration data are presented as rates of percentage and analyzed by the Chi-square test. A P value of $<0.05$ was considered to be statistically significant. 


\section{RESULTS}

\section{Comparison of the secretion levels of TGF- $\beta$ in each group of CD4+ T cells}

Compared with the control group, the secretion level of TGF- $\beta$ increased close to 2.5 times in CD4+ T cells treated with sirolimus; the difference was statistically significant $(P<0.01)$. The secretion level decreased in cells treated with cyclosporin A compared with the control group, but the difference was not statistically significant $(P>0.05)$ (Figure 1).

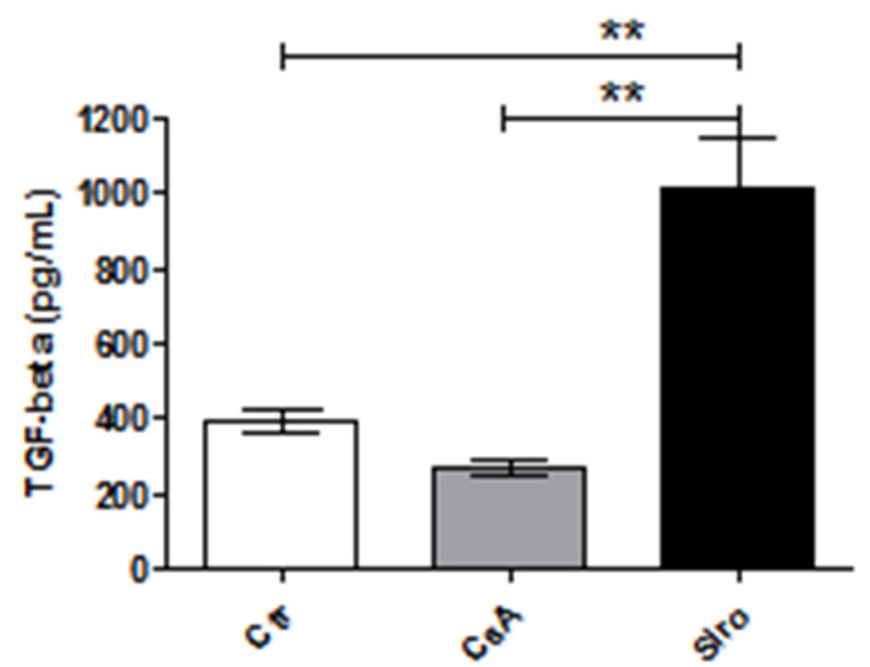

Figure 1. Comparison of the secretion levels of TGF- $\beta$ in each CD4+ T cell group. Sirolimus-treated group increased $2.5 X$ over control levels $(1016.6666 \pm 126.9509$ vs $395.5208 \pm 29.75066) .{ }^{* *} \mathrm{P}<0.01$. Ctr, control; CsA, cyclosporine A; Siro, sirolimus.

\section{Comparison of the proliferation of each CD4+ T cell group}

Compared with control group, sirolimus and cyclosporin A could significantly inhibit the proliferation of T cells induced by aCD3 monoclonal antibody $(P<0.01)$. However, there was no statistically significant difference between the inhibitory effects of sirolimus and cyclosporin $A(P>$ 0.05) (Figure 2).

\section{Comparison of the proportion of CD4+ CD25+ Treg cells to CD4+ T cells in each group}

The flow cytometric detection results showed that the rate of CD4+ CD25+ Treg cells in the CD4+T cell population was $65.21 \%$ in the sirolimus group, which was slightly lower than that in the negative control group $(69.22 \%)$; the difference was not statistically significant $(P>0.05)$. However, the rate was $41.25 \%$ in the cyclosporin A group, which was significantly lower than that in the negative control group $(69.22 \%)(P<0.01)$ (Figure $3 A-C)$. 


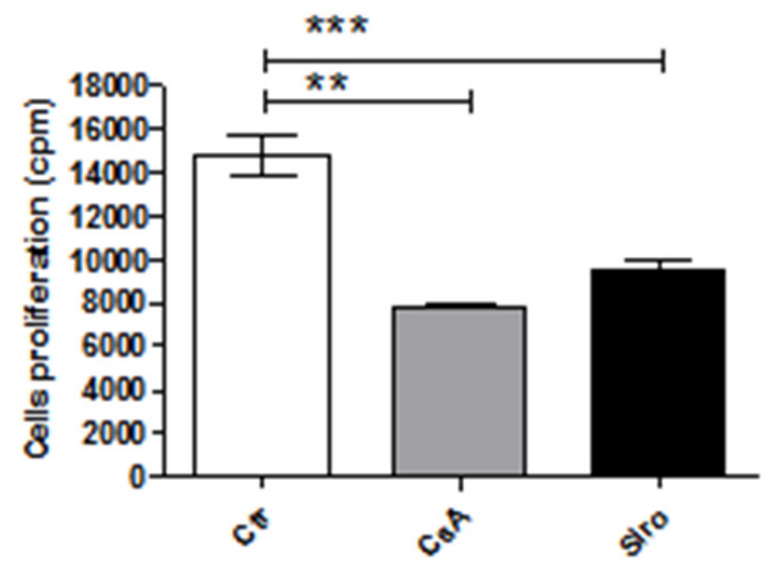

Figure 2. Comparison of the proliferation of each group of CD4+ T cells. ${ }^{* *}$ Compared with the control group, $P<0.01$. CsA, cyclosporine A; Siro, sirolimus.
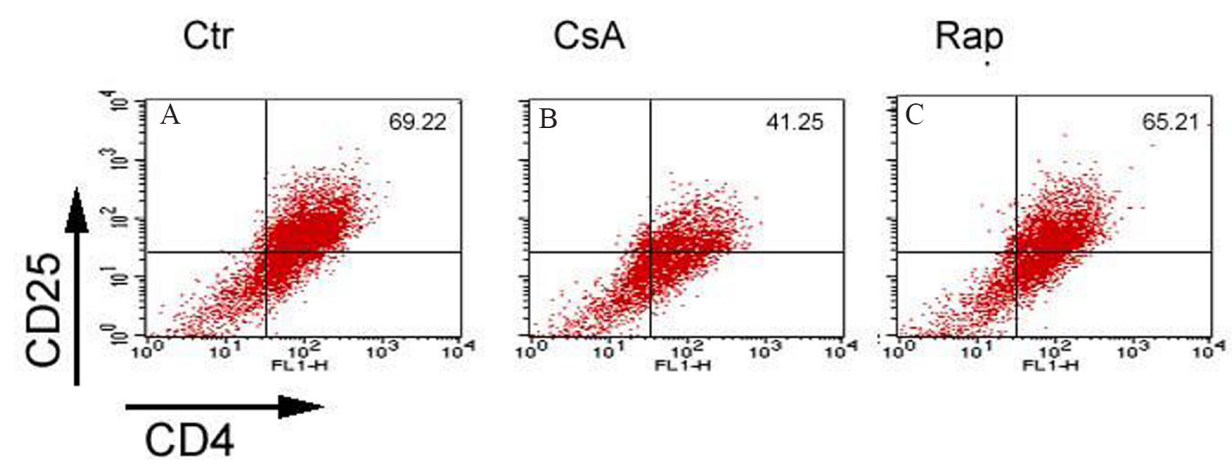

Figure 3. Comparison of the proportions of $C D 4+C D 25+$ Treg cells to $C D 4+T$ cells in each group using flow cytometry. Ctr, control; CsA, cyclosporine A; Siro, sirolimus.

\section{Comparison of the expression of Foxp3 in the CD4+ CD25+ T cells in each group}

The rate of FoxP3+ T cells in the sirolimus group was significantly higher than that in the control group (53.7 vs 40.2\%, P < 0.05). In contrast, the FoxP3+ rate in the cyclosporin A group was significantly lower than that in the control group; the difference was statistically significant (23.6 vs $40.2 \%, P<0.01$ ) (Figure 4A-C).

\section{Comparison of the ability for MLR system reaction inhibition by CD4+ CD25+ T cells treated with sirolimus}

CD4+ CD25- T cells barely proliferated without any stimulation, whereas their proliferation was significant after adding into stimulation in ratio of 10:1 in the MLR system. In contrast, the reactive cells that had been stimulated to proliferate could be subsequently inhibited by the MLR system comprising a mixture of CD4+ CD25+ T cells treated with sirolimus and reactive cells in different ratios $(1: 1,1: 2$, and 1:4) (Figure 5). 


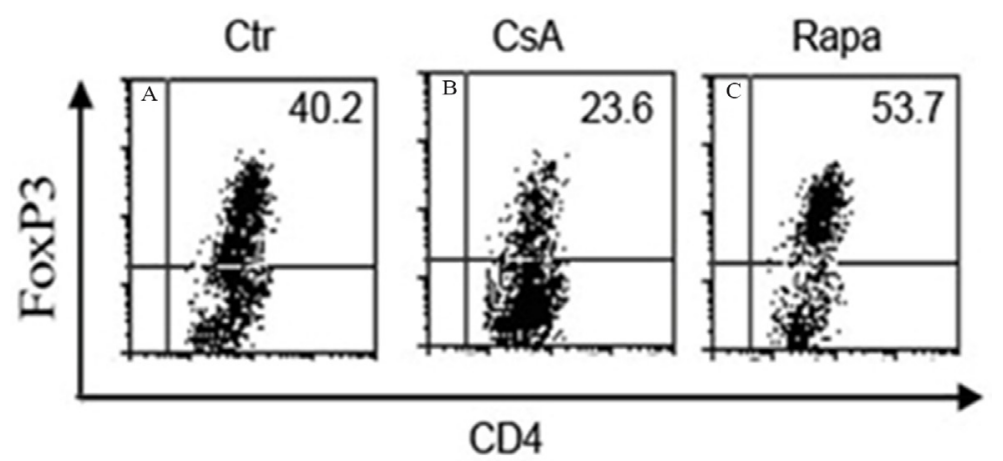

Figure 4. Comparison of the expression of Foxp3 in the CD4+ CD25+ T cells in each group by flow cytometry. Ctr, control; CsA, cyclosporine A; Siro, sirolimus.

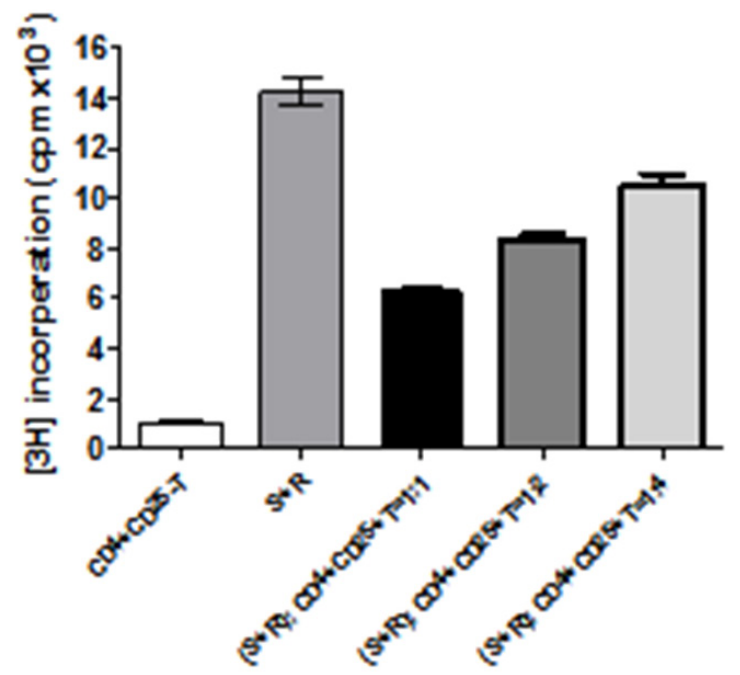

Figure 5. Comparison of the ability of inhibiting the MLR system reaction by CD4+CD25+ T cells treated with sirolimus. $\mathrm{S}$, stimulated cells; R, reactionary cells.

\section{DISCUSSION}

Sirolimus is similar to the immunosuppressive agents FK506 and cyclosporin A in structure, and it functions in combination with intracellular FK506 binding protein (FKBP12). However, unlike FK506 and cyclosporin A, sirolimus does not inhibit the activity of calcineurin induced by $\mathrm{T}$ cell receptors (Ma et al., 2008). In addition, the sirolimus-FKBP12 complex can inhibit serine/threonine protein kinases (the mammalian targets of sirolimus) that are needed for protein synthesis and the progression of the cell cycle. Sirolimus inhibits the reactive signaling of cytokine growth factors, whereas FK506 and cyclosporin A play their roles by inhibiting the induction and activation of TCRs (Battaglia et al., 2005; Strauss et al., 2007). Thus, sirolimus can inhibit the progression of cells from the $\mathrm{G} 1$ to $S$ phase in the cell cycle of T cells, promote T cell anergy induced by TCR (even including co-stimulation), and allow for the induction of operating tolerance. Furthermore, 
the combination of sirolimus and FKBP-12 can counter the inhibitory effects of FKBP-12 on the signaling pathway mediated by TGF- $\beta$, which suggests that sirolimus might have an effect on the TGF- $\beta$ signaling pathway. As a new immunosuppressive agent, sirolimus was found to have greater immunosuppressive effects than cyclosporin A (Takemoto et al., 2006), but the underlying mechanism is unclear.

TGF- $\beta$ is a multi-function cytokine that can influence many cell types. It can mediate apoptosis; and stimulate the growth of fibroblasts and the generation of extracellular matrix. In addition, it plays an important role in the immunoregulation and anti-inflammatory effects of the immune system; for example, by inhibiting the proliferation of T and B cells, inactivating macrophages, and promoting the immune deviation of TH1 and TH2 (Sad and Mosmann, 1994; Tsunawaki et al., 1998). In certain models, exogenous TGF- $\beta$ can delay allograft rejection and relieve the degree of autoimmune disease. Furthermore, mutation of the TGF- $\beta$ coding gene in mouse can result in the severe inflammation of various organs and even can lead to premature death, which suggests that cytokines play critical roles in immunoregulation (Perruche et al., 2008; Delisle et al., 2013).

Liu et al. (2008) revealed that TGF- $\beta$ signaling was indispensable for the development of CD4+ CD25+ Foxp3+ Treg cells in the thymus and could induce the fibrosis of transplanted organs and tissues, and that increase of its expression could be beneficial for the inhibition of acute immune responses in the early stage of allograft rejection. However, the continuous expression of TGF- $\beta$ could increase the fibrosis of transplanted organs and tissues and result in chronic rejection. Immediately following secretion, TGF- $\beta$ remains in an inactive state, whereas the combination of sirolimus and FKBP-12 could counter the inhibitory effects of FKBP-12 on TGF- $\beta$ RI, promote the combination of TGF- $\beta$ and the heterodimer receptor complex of TGF- $\beta$ RI and TGF- $\beta$ RII, and activate the cellular kinase domain of the receptor, leading to the phosphorylation and activation of members of the Smad family and thus regulating the transcription and expression of genes dependent on TGF- $\beta$ (Letterio and Roberts, 1998). Therefore, sirolimus could promote the activation of TGF- $\beta$.

An increasing number of studies have confirmed that TGF- $\beta$ plays key roles in the differentiation and proliferation of CD4+ CD25+ Treg cells. The CD4+ CD25+ Treg cell represents a class of $T$ cells with immunosuppressive effects, with different functions from those of $T$ cell subsets with immunosuppressive effects in Th1 and Th2; it can actively participate in the regulation of immune response and tolerance and plays critical roles in the regulation of self-tolerance, and of tumor and transplantation immunity (Centuori et al., 2012). Though CD4+ CD25+ T cells play critical roles in the induction and maintenance of the tolerance to transplanted organs, the influence on CD4+ CD25+ T cells of immunosuppressive agents that have been widely applied to treat organ transplantation rejection has been unclear until recently. Studies have suggested that different immunosuppressive agents had different effects on CD4+ CD25+ T cells, with some inhibiting rejection and blocking the activation and establishment of immune tolerance. In contrast, the most recent study has shown that sirolimus and other immunosuppressive agents have roles in promoting the proliferation of CD4+ CD25+ T cells in vitro (Keever-Taylor et al., 2007). However, the molecular mechanism of sirolimus on the production of Treg cells remained unclear.

In this study, we investigated whether sirolimus promoted the proliferation of CD4+ CD25+ Foxp3+ Treg cells through TGF- $\beta$ to understand the molecular mechanism underlying its roles in immunoregulation and its effects on promoting the production of the Treg cells. We further discussed whether the proliferation of CD4+ CD25+ Treg cells could be induced by immunosuppressive agents, which would thereby improve their ability of immune suppression of reactive cells at organ transplantation sites. This would be beneficial for the establishment of transplantation tolerance and long-term survival of organ grafts. 
The results of this study showed that sirolimus could significantly increase the secretion level of TGF- $\beta$ in CD4+ T cells compared with the untreated control group; in contrast, the secretion level was decreased in the group treated with cyclosporin $A$. The results of detection of the proliferation of CD4+ T cells by the $\left[{ }^{3} \mathrm{H}\right]-\mathrm{TdR}$ incorporation method found that sirolimus and cyclosporin A could both significantly inhibit the proliferation of T cells stimulated by aCD3 monoclonal antibodies. However, there was no statistically significant difference in the inhibitory effects of sirolimus and cyclosporin $A(P>0.05)$. The result of flow cytometric analysis demonstrated that the rate of CD4+ CD25+ Treg cells in the CD4+ T cell population in the sirolimus group was slightly lower than that in the negative control group, but the difference was not statistically significant $(P>0.05)$; in contrast, the proportion in the cyclosporin A group was significantly lower than that in the negative control group $(P<0.01)$. The rate of FoxP3 $+T$ cells in the sirolimus group was significantly higher than that in the control group $(P<0.05)$; while the rate in the cyclosporin $A$ group was significantly lower $(P$ $<0.01)$. We studied the inhibitory effects of sirolimus on CD4+ CD25+ Treg cells further and found that sirolimus could significantly improve the inhibitory ability of CD4+ CD25+ Treg cells on CD4+ CD25- T cells in the MLR reaction compared with the control group.

Overall, we demonstrated that sirolimus had roles in promoting the proliferation of the CD4+ CD25+ Treg cell subset in vitro and in promoting the expression of FoxP3+ in these cells, whereas cyclosporin A could significantly inhibit the proliferation of the CD4+ CD25+ Treg subset and the expression of FoxP3+. Sirolimus could also promote the secretion of TGF- $\beta$, promote the phosphorylation of Smad-2/3, and thus activate the TGF- $\beta$ signal pathway, promoting the proliferation of the CD4+ CD25+ Treg cell subset and the expression of FoxP3+, which suggested that sirolimus might participate in anti-transplant rejection by improving the function of CD4+ CD25+ Treg cells.

\section{Conflicts of interest}

The authors declare no conflict of interest.

\section{ACKNOWLEDGMENTS}

Research supported by the National Natural Sciences Foundation of China (\#81370230 and \#81570279), the Technology Foundation for Selected Overseas Chinese Scholar, Ministry of Human Resources and Social Security of China (P. Zhu, \#Z012013046), and the Science and Technology Program of Guangzhou China (\#201508020107).

\section{REFERENCES}

Battaglia M, Stabilini A and Roncarolo MG (2005). Rapamycin selectively expands CD4+CD25+FoxP3+ regulatory T cells. Blood 105: 4743-4748.

Burchill MA, Yang J, Vogtenhuber C, Blazar BA, et al. (2007). IL-2 receptor beta-dependent STAT5 activation is required for the development of Foxp3+ regulatory T cells. J. Immunol. 178: 280-290.

Centuori SM, Trad M, Lacasse CJ, Alizadeh D, et al. (2012). Myeloid-derived suppressor cells from tumor-bearing mice impair TGF- $\beta$-induced differentiation of CD4+CD25+FoxP3+ Tregs from CD4+CD25-FoxP3- T cells. J. Leukoc. Biol. 92: 987-997.

Delisle JS, Giroux M, Boucher G, Landry JR, et al. (2013). The TGF- $\beta$-Smad3 pathway inhibits CD28-dependent cell growth and proliferation of CD4 T cells. Genes Immun. 14: 115-126.

Keever-Taylor CA, Browning MB, Johnson BD, Truitt RL, et al. (2007). Rapamycin enriches for CD4(+) CD25(+) CD27(+) Foxp3(+) regulatory T cells in ex vivo-expanded CD25-enriched products from healthy donors and patients with multiple sclerosis. Cytotherapy 9: 144-157. 
Lan RY, Ansari AA, Lian ZX and Gershwin ME (2005). Regulatory T cells: development, function and role in autoimmunity. Autoimmun. Rev. 4: 351-363.

Letterio JJ and Roberts AB (1998). Regulation of immune responses by TGF-beta. Annu. Rev. Immunol. 16: 137-161.

Liu Y, Zhang P, Li J, Kulkami AB, et al. (2008). A critical function for TGF-beta signaling in the development of natural CD4+CD25+Foxp3+ regulatory T cells. Nat. Immunol. 9: 632-640.

Ma X, Lu YP, Yang L, Song J, et al. (2008). Rapamycin and cyclosporine have different effects on expression of Ang-1 and Ang-2 and Tie2 in rat renal allograft with chronic allograft nephropathy. Transplant Proc. 40: 2804-2807.

Perruche S, Zhang P, Liu Y, Saas P, et al. (2008). CD3-specific antibody-induced immune tolerance involves transforming growth factor-beta from phagocytes digesting apoptotic T cells. Nat. Med. 14: 528-535.

Sad S and Mosmann TR (1994). Single IL-2-secreting precursor CD4 T cell can develop into either Th1 or Th2 cytokine secretion phenotype. J. Immunol. 153: 3514-3522.

Sakaguchi S (2004). Naturally arising CD4+ regulatory T cells for immunologic self-tolerance and negative control of immune responses. Annu. Rev. Immunol. 22: 531-562.

Strauss L, Whiteside TL, Knights A, Bergmann C, et al. (2007). Selective survival of naturally occurring human CD4+CD25+Foxp3+ regulatory T cells cultured with rapamycin. J. Immunol. 178: 320-329.

Taams L, Vukmanovic-Stejic M, Salmon M and Akbar A (2003). Immune regulation by CD4+CD25+ regulatory T cells: implications for transplantation tolerance. Transpl. Immunol. 11: 277-285.

Takemoto N, Intlekofer AM, Northrup JT, Wherry EJ, et al. (2006). Cutting edge: IL-12 inversely regulates T-bet and eomesodermin expression during pathogen-induced CD8+ T cell differentiation. J. Immunol. 177: 7515-7519.

Tsunawaki S, Sporn M, Ding A and Nathan C (1988). Deactivation of macrophages by transforming growth factor-beta. Nature 334: 260-262.

Yao Z, Kanno Y, Kerenyi M, Stephens G, et al. (2007). Nonredundant roles for Stat5a/b in directly regulating Foxp3. Blood 109: 4368-4375.

Zeiser R, Leveson-Gower DB, Zambricki EA, Kanbham N, et al. (2008). Differential impact of mammalian target of rapamycin inhibition on CD4+CD25+Foxp3+ regulatory T cells compared with conventional CD4+ T cells. Blood 111: 453-462.

Zheng SG (2008). The critical role of TGF-beta1 in the development of induced Foxp3+ regulatory T cells. Int. J. Clin. Exp. Med. 1: 192-202. 